Comparison of results of colour coded duplex sonography and venography in patients with suspected femoropopliteal vein thrombosis and sensitivity, specificity, and positive and negative predictive values of colour coded duplex sonography ( $95 \%$ confidence intervals)

Colour coded duplex sonography

Vein incompressibility Absence of flow phasicity Visualisation of thrombus

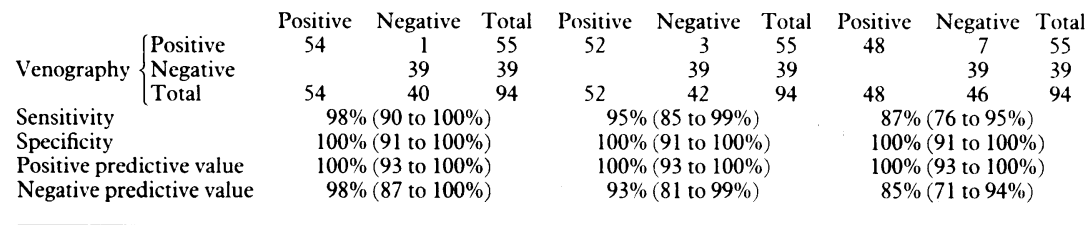

offers simultaneous visualisation of real time B-mode images and flow by pulsed colour coded Doppler sonography.

In our study the best diagnostic criterion was incompressibility. The only false negative result was during the early phase of the study in a patient with a thrombus limited to the adductor canal. Since this case no further isolated adductor canal thrombosis has been missed by accurate examination of this region. This confirms other reports that the assessment of vein incompressibility is the most reliable criterion for deep vein thrombosis. ${ }^{5}$

Colour coded visualisation of venous flow has considerable diagnostic advantages in that it more successfully detects a non-occlusive free floating thrombus with visible flow around it, which is known to be a high risk for thromboembolism. Moreover, a fresh hypoechogenic thrombus may be misinterpreted by conventional duplex sonography. Another advantage is the quick and reliable identification of vascular structures, especially in the popliteal fossa, where accessory veins are not easily distinguishable from other structures. Colour coded duplex sonography can be performed at the bedside, is time sparing, and permits diagnosis of other abnormalities that mimic deep vein thrombosis-for example, haematoma, Baker's cyst, and neoplasm.

We conclude that colour coded duplex sonography is a highly accurate, simple, non-invasive method for detecting femoropopliteal thrombosis. Additional venography is not necessary. Its value in diagnosing isolated calf vein thrombosis remains to be established.

1 Hirsh J, Hull RD, Raskob GE. Clinical features and diagnosis of venous thrombosis. I Am Coll Cardiol 1986;8:114-27B.

2 Sandler DA, Mitchell JRA. How do we know who has had deep vein thrombosis? Postgrad Med f 1989;65:16-9.

3 Bettmann MA, Paulin S. Leg phlebography: the incidence, nature and modification of undesirable side effects. Radiology 1977;122:101-4.

4 Rabinov K, Paulin S. Roentgen diagnosis of venous thrombosis in the leg. Arch Surg 1972;104:134-44.

5 Lensing AWA, Prandoni P, Brandies D, et al. Detection of deep-vein thrombosis by real-time B-mode ultrasonography. $N$ Engl 7 Med $1989 ; 320: 342-5$.

(Accepted 31 August 1990)

\section{Are falls from supermarket trolleys preventable?}

\author{
Margaret Campbell, James Ferguson, \\ Thomas F Beattie
}

\begin{abstract}
Accident and Emergency
Department, Royal

Aberdeen Children's

Hospital, Cornhill Road,

Aberdeen AB9 2ZB

Margaret Campbell, MRCGP,

senior house officer

James Ferguson, FRCSED, registrar

Thomas F Beattie, FRCSED, consultant
\end{abstract}

Correspondence and requests for reprints to: $\mathrm{Mr}$ Beattie.

BrMed F 1990;301:1370
Children are commonly transported around supermarkets in the seat of a supermarket trolley. Usually no restraint is fitted, making it easy for a child to stand up. We report a series of falls from such trolleys and discuss some preventive measures.

\section{Patients, methods, and results}

All children presenting to this department after a fall from a supermarket trolley were prospectively recorded over six months. During this time 8215 children attended the department, 10 of whom had fallen out of a trolley and injured their head. The details of their injuries are shown in the table. None of the children had been restrained. Their mean age was 24 months (range 9-50 months). Three children were admitted to hospital, one of whom had sustained an occipital fracture.

Details of children with head injuries who fell from supermarket trolleys

\begin{tabular}{cccccc}
\hline Child & Sex & Age (months) & $\begin{array}{c}\text { Loss of } \\
\text { consciousness }\end{array}$ & Skull fracture & Outcome \\
\hline 1 & F & 18 & No & No & Discharged with instructions about head injuries \\
2 & F & 13 & No & No & Discharged with instructions about head injuries \\
3 & F & $9 \cdot 5$ & No & No & Discharged with instructions about head injuries \\
4 & F & 42 & No & No & Discharged with instructions about head injuries \\
5 & M & 23 & No & No & Discharged with instructions about head injuries \\
6 & M & 13 & No & No & Discharged with instructions about head injuries \\
7 & M & 40 & No & No & Discharged with instructions about head injuries \\
8 & M & 9 & Yes & No & Observed for 8 hours \\
9 & F & 20 & Yes & No & Observed for 24 hours \\
10 & F & 50 & No & Yes & Observed for 24 hours \\
\hline
\end{tabular}

To identify preventive measures we went to six supermarkets chosen at random. Details of 50 consecutive children placed in a trolley in each supermarket were recorded. Of these 300 children, only six were restrained with a child harness. None of the trolleys was fitted with a restraining device.

\title{
Comment
}

We believe that we are the first group to report this type of injury. The fact that all the children in this study received a head injury shows the ease with which children fall head first. Despite the small number of children a third were admitted to hospital but none had appreciable intracranial abnormality. Few of the other mechanisms of injury gave such a high admission rate. These children, however, represent a group in whom the accident is easily preventable.

Using child restraints and harnesses has become "outdated," but we believe that they could help to reduce this type of fall. During our study we became aware of a recently developed restraint designed to prevent such accidents. ' We recommend that all supermarkets that provide trolleys should be encouraged to provide the means to restrain a child within the trolley to help to reduce the incidence of this type of accident. Parents should be made aware of the benefits of using a restraint or harness and be encouraged to use these. We recommend that advice on child restraints should be included in all publications on prevention of accidents in children. Child surveillance programmes in general practice should also include such advice.

\section{We thank Miss L McHattie for typing the manuscript.}

1 Anonymous. Shopping safely. Practical parenting 1990; January/February:40. 